\title{
A Hybrid Shape Optimization Approach for Complex Applications in Computational Fluid Dynamics
}

\author{
Régis Duvigneau, Michel Visonneau, Ecœele Centrale de Nantes ${ }^{1}$
}

\section{Introduction}

Computational Fluid Dynamics (CFD) flow selvers have been integrated in fully automated design optimization procedures. In hydredynamics and ship building industries, potential flow selvers were first included in the design loop for the sakc of robustness and low computational cffort, Maisonneuve et al. (1996), Rosetti et al. (1999), Yasukawa (2000), Hendrix et al. (2001), Peri et al. (2000,2001). The reduction of the wave resistance is usually aimed at. Howcver, a morc accuratc prediction of the flow may be requircd, for instance for drag minimization or when precisc characteristics of the flow arc considered as optimization objective. Therefore visceus flow solvers were included in hull shape optimization proccdurcs, Jansson and Larsson (1996), Hino (1999), Chen and Huang (2002), Duvigneau and Visøneau (2003). The implementation of such complex flow solvers in a shape optimization procedure introducc some additional difficultics.

The physical and gcometrical configurations cncountcred in industrial applications of ten requirc visceus flow solvers with sephisticated turbulence models capable of dealing with realistic geometries. The naive use of a standardized toolbox optimization software connected to a flow solver and an automated grid generater is not a sensible strategy. Instead the peculiarities of the flow solver should be taken into account. E.g. the constraints on the grid $\left(y^{+}=O(1)\right.$ near the wall) linked to the use of near-wall turbulence models will have serious consequences on the mesh update precedure. If a particular strategy taking into accunt the high stretching of the volumes near the wall is not included, the mesh update will fail. Anether reason is related to the mandatory use of parallelizatien strategies, such as demain decomposition, as soon as 3-d problems are considered. The mesh update, as well as the parameterization of the shape, should be adapted to this multi-bleck partition to work within each block independently and to send information for updating the overall domain. Otherwise, the parallelization becomes useless. The high computatienal costs implied by 3 - $\mathrm{d}$ calculatiens, as well as the possible occurrence of numcrical noises of various origins during the evaluations, sheuld bc taken into accunt for the choicc of an optimization stratcgy. Finally, if different connected programs arc employed in the design loop, some practical difficultics may arise, when distant cemputcrs are involved in the optimization precess. All these remarks motivated the development of an optimization procedure, in which all numerical toels are adapted to the flow solver and integrated into a single code.

\section{The ISIS flow solver}

The flow solver ISIS (devcloped in our laboratery) is included in the design procedurc. It solves the incompressible Reynolds-Averaged Navier-Stokes Equations (RANSE) on unstructured grids, with a strongly conscrvative formulatien:

$$
\begin{gathered}
\frac{\partial}{\partial t} \int_{V} \rho d V+\int_{S} \rho\left(\vec{U}-\vec{U}_{d}\right) \cdot \vec{n} d S=0 \\
\frac{\partial}{\partial t} \int_{V} \rho U_{i} d V+\int_{S} \rho U_{i}\left(\vec{U}-\vec{U}_{d}\right) \cdot \vec{n} d S=\int_{S}\left(\tau_{i j} I_{j}-p I_{i}\right) \cdot \vec{n} d S+\int_{V} \rho g_{i} d V \quad i=1,2,3
\end{gathered}
$$

$V$ is the domain of interest, or contrel volume, bounded by the closed surface $S$ moving at the vclocity $\vec{U}_{d}$ with a unit normal vector $\vec{n}$ directed $\bullet$ utward. $\vec{U}$ is the velocity, $p$ the pressure. $\tau_{i j}$ and $g_{i}$ are the

\footnotetext{
${ }^{1} 1$ rue cle la Nøe, F-44321 Nantes, France, Michel.Visonneau@ec-nantes.fr
} 
components of the viscous stress tensor and the gravity, $I_{j}$ a vector with compenents zero except for the component $j$ which is 1 .

The discretization scheme uses a finite-volume method, generalized to unstructured meshes composed of arbitrary volume shapes. Thus, calculations involving complex grids may be taken into account. The flow variables are stored at the center of the control volumes, surface and volume integrals being evaluated using second-order accurate approximations. The pressure-velocity coupling is pcrformed by a SIMPLE-likc algorithm. Scveral ncar-wall løw Rcynolds numbcr turbulcnce mødcls, ranging frem one-equation Spalart-Allmaras medel, Spalart and Allmaras (1991), two-equation k- $\omega$ models, Menter (1993), to a full Reynolds stress transport $R_{i j}-\omega$ model, Deng and Visonneau (2000), are implemented in the flow selver.

\section{Optimization strategies}

Scveral stratcgics may be considered to lcad the scarch of the optimal shapc. In order to reducc the computational costs, $\bullet$ ne may propose to usc gradicnt-bascd meth $\bullet$ ds, charactcrized by a super-linear convergence and a weak dependency on the number of design parameters. However, the implementation of this stratcgy in a cemplex numcrical framcwerk is particularly tcdious. Indccd, the evaluation of the derivatives of the objective function with respect to the design parameters relics on the differentiation of the flew selver, threugh the resolutien of an adjeint cquation, Anderson and Venkatakrishnan (1999), Jameson et al. (1998). Thus, this approach is still limited to mildly complex problems, involving typically inviscid flows. Some viscous flow solvers were linearized with success, but with some limitations, as pointed out in Hino (1999). Two alternative approaches may be considered to evaluate the derivatives: autematic differentiation software, Hovland et al. (1997) and an incomplete evaluation of the gradient, Mohammadi (1999), Mohammadi et al. (2000), neglecting the modifications of the flow. These methods are still limited (by the complexity of flow solver in the first case and the range of application in the secend case) and gradient-based methods have scveral drawbacks: they can only censider onc optimizatien critcrion and arc particularly scnsitive to the numerical neise arising frem the use of complex numerical metheds and generating spurious local optima. Considering all these remarks, the usc of gradicnt-bascd stratcgics may not be se wisc in such a context. However, the cheice to reject gradient-based methods has crucial consequences, since all other approaches arc submitted to the "cursc of dimensienality", the number of cvaluations requircd growing more than linearly with the dimension of the problem. Thus, the parameterization of the shapes sheuld involvc as few design variables as possible.

Derivative-frce detcrministic algørithms, such as the simplex methed, Nelder and Mead (1965), based only on function values comparisons, may be easily implemented in the design procedure, since the flow solver is considered as a "black box", yielding both flexibility and robustness to solve complex optimization problems, Duvigneau and Visonneau (2001a), while being less sensitive to the noisy errors. Nevertheless, they are still limited to lecal optimizations including one criterion.

Stochastic methods, such as Genctic Algorithms (GAs), Goldberg (1989), arc particularly appcaling, as they allow gløbal optimizations and concept expleration in multi-øbjective problems. Their robustness and capability te sølvc multi-medal problems have becn demonstrated •ften, Kitamura et al. (2000), Yasukawa (2000), Maisonneuve et al. (2002). As derivative-free methods, they allow easy implementation of complex CFD applications, Duvignea and Visonneau (2001b). Howcver, GAs arc particularly expensive, since the number of evaluations is about ten times higher than the number required by detcrministic methods. These cests makc GAs often unrcalistic for 3-d CFD problcms.

One may combine the advantages of the different strategies and use approximation methods to reduce the computational time. GAs have two main drawbacks: the number of evaluations and the low local convergence rate. To reduce the number of evaluations through the flow solver, one may use the knowledge already collected on the problem to build local approximations replacing some expensive evaluations, Giotis and Giannakoglou (1999,2000). More precisely, all exact evaluatiens by 
the flow solver during the optimization precedure are støred in a database, used to train Artificial Ncural Networks (ANNs). They arc cmployed te perform approximatc pre-cvaluations of the shapcs at each generation. Only the most promising shapes are then exactly evaluated by the flow solver. This reduccs the number of expcnsive cvaluations significantly, without losing the intcresting capabilitics of genetic algorithms. A hybridization technique is proposed to improve the low local convergence rate of GAs in the vicinity of the solution: the GAs detcrminc the ovcrall charactcristics of the optimal shape and the final precise local search is performed by a deterministic algorithm.

This strategy, based on hybrid genetic algorithms and neural networks, has been successfully applied to the eptimization of the shape of a 3 -d wing at $8^{\circ}$ incidence with respect to the lift, Duvigneau and Visonnea (2002). Recently, a new $\bullet$ ptimization exercise was performed with the same configuratiøn. The goal of this exercise was the reduction of the intensity of the longitudinal vertex generated at a salmon. The vorticity modulus is used as objective function. For this case, an unstructured mesh of about 800,000 cells was used, for a Reynolds number $R_{n}=2 \cdot 10^{6}$, employing the near-wall low Reynelds number SST $k$ - $\omega$ model. The shape modifications, located in the vicinity of the salmon, are described by 6 design parameters. Fig.1 illustrates the strategy. For some generations, all evaluations are performed exactly by the flow solver to build a coarse database. Then, the approximate preevaluations procedure is activated, reducing strongly the number of expensive evaluations. Finally, when the best solution found by GAs scem to be close to the optimal shapc, a detcrministic approach is used to reach quickly the selution. A reduction of $12 \%$ of the verticity modulus is observed. The usc of the detcrministic method alone leads te a poor improvement, Fig.l.

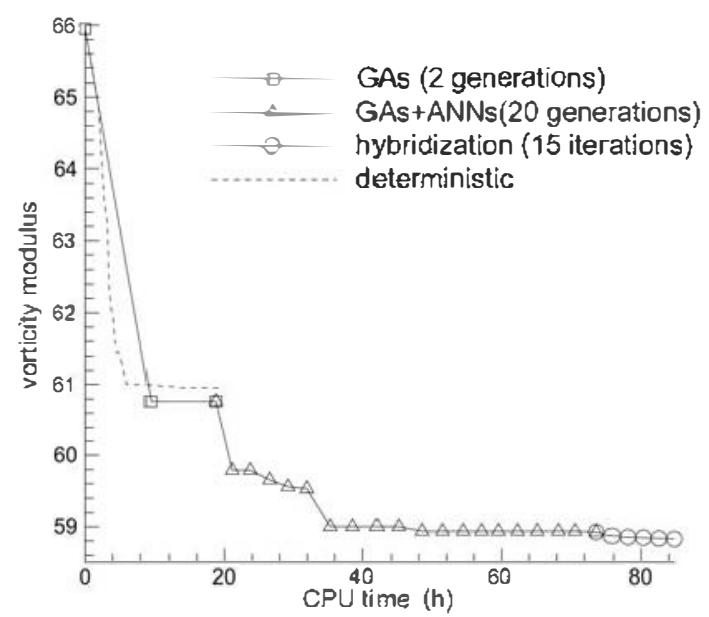

Fig.1: Evolution of the objective function

Thus, very complex problems may be solved using this strategy. Even if the costs remain high (although calculations were performed on 60 processors), the CPU time has been reduced more than five times with respect to a simple genetic algorithm. Althøugh this appreach still has seme limitations, such as the number of design variables involved, it seems to be a realistic and promising way.

\section{Shape parameterization}

When 3-d unstructured meshes are employed, the parameterization of the shape required by the design process is difficult. A curvilinear representation of the shape is not available. Thus, the use of $\mathrm{B}$-spline net representations is tedious. The nodes ceordinates on the shape and connectivities are the only knowledge which could be used. Therefore, a Free Form Deformation (FFD) technique, Sederber and Parry (1986) is proposed to control the shape perturbations during the design process. It consists in first ernbedding the object to be deformed in a box, and then in modifying the metrics of the space

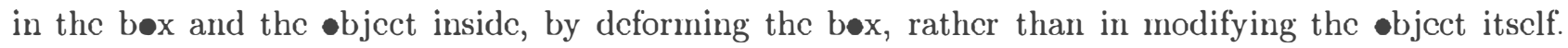


Thus, the shape of the object can be modified without even identifying its nature. Actually, a local coordinatc systcm is attached on a parallel-cpipcdic volume including the object to be deformed. The coordinates of any point $P$ in this reference system are :

$$
P=\xi \vec{e}_{1}+\eta \vec{e}_{2}+\zeta \vec{e}_{3}
$$

$\vec{e}_{1}, \vec{e}_{2}$ and $\vec{e}_{3}$ are vectors of unit length, parallel to the leading directions of the parallel-epipedic volume. A mapping function is then applied to the space inside the velume, by the use of a trivariate B-spline product. The new position $P_{F F D}$ of the previous point $P$ is provided by the algebraic relation:

$$
P_{F F D}=\sum_{i, j, k} N_{i}(\xi) N_{j}(\eta) N_{k}(\zeta) P_{B S}^{i j k}
$$

$N_{i}, N_{j}$ and $N_{k}$ are the B-spline basis functiens and $P_{B S}^{i j k}$ are the Cartesian coordinates $\bullet$ the control points. By moving some of these control points, the metrics of the space in the parallel-epipedic volume arc modificd, yiclding a smooth deformation of the shapc insidc. This appreach provides an easy-to-use selution, requiring enly a few control points to control the deformation of the shape. However, this gencral tcchnique may bc inadequatc to deal with a particular and spccializcd problcm.

\section{Mesh update}

The automated mesh update is problematic, when unstructured grids using a near-wall turbulence modeling formulation are empleyed, since the grid volumes are highly stretched near the wall to fulfill the condition $y^{+} \leq 1$. Therefore, a classical spring analogy based $\bullet$ linear springs will fail, Anderson and Venkatakrishnan (1999). We used a powcrful method bascd on both lincar and torsional spring analogy, Farhat et al. (1998), with success for 2-d two-dimensional shape optimization problems, Duvigneau and Visonneau (2001a). But this morc complicatcd approach may hardly be cmploycd for 3-d preblems. Therefore, one may recommend to smoothly deform the shape and the mesh by the FFD method at the same time, since the FFD approach relies on a spatial deformation. This strategy may be carricd out for 2-d as wcll as 3-d grids and is $\bullet$ bviously adcquatc for multi-block calculatiens. However, the quality of the resulting grid is not ensured. Figs. 2 to 4 show an example of deformation of a hybrid grid around the NACA 0012 airfoil. The FFD method provides a smoother deformatien, but the erthogonality of the grid near the wall is not maintained, contrary to the spring analogy. Nevertheless, the FFD method gives satisfactory results, when reasonable perturbations are taken into account.

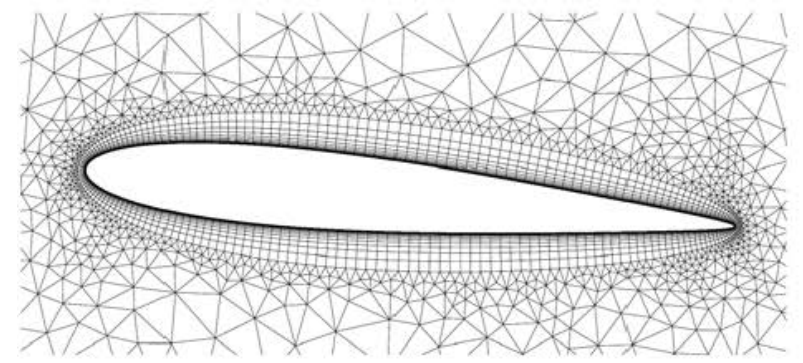

Fig.2: Initial mesh

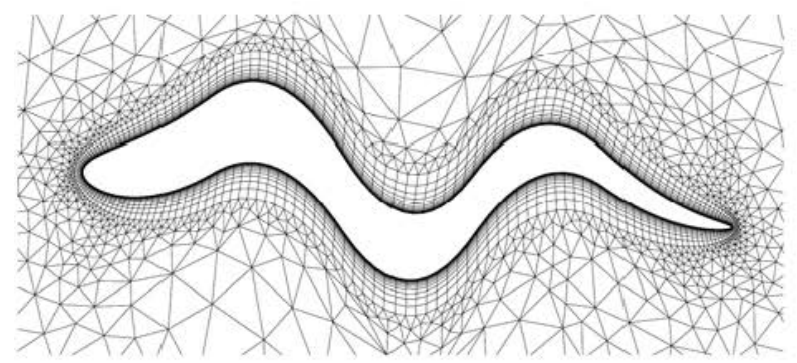

Fig.4: Free form deformation

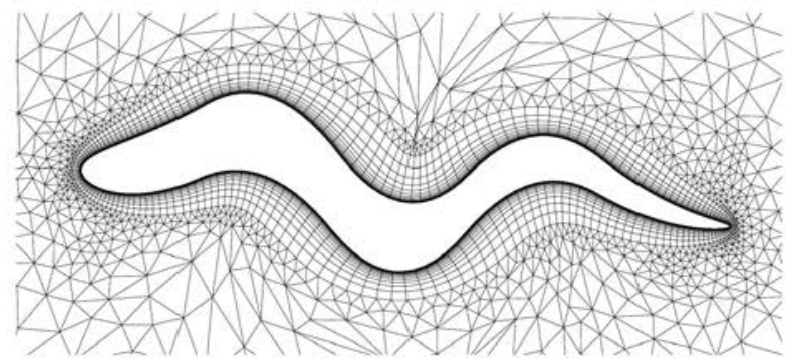

Fig.3: Spring analogy

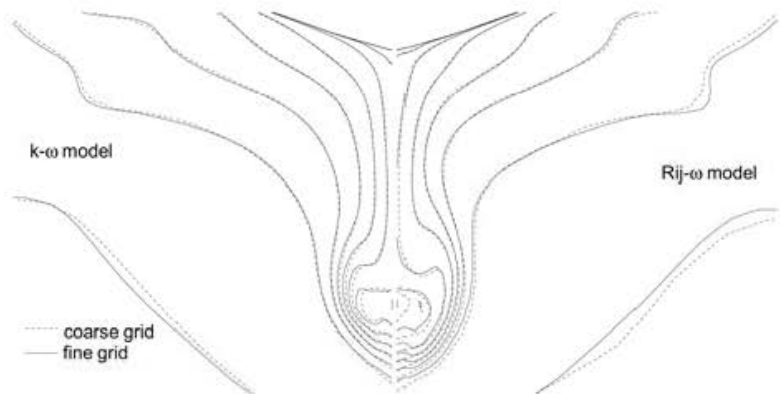

Fig.5: Isowakes at full scale for two grids and two turbulcnce modcls 


\section{Influence of turbulence modeling}

Several quantities influence the predicted flow and thus on the search for an optimum: grid size, stopping criteria, discretization schemes, turbulence modeling, etc. generate noisy errors during the evaluations, Grossman et al. (2002), Madsen (2000). Duvigneau et al. (2002) studied in depth the role played by turbulence models for hull shape optimization.
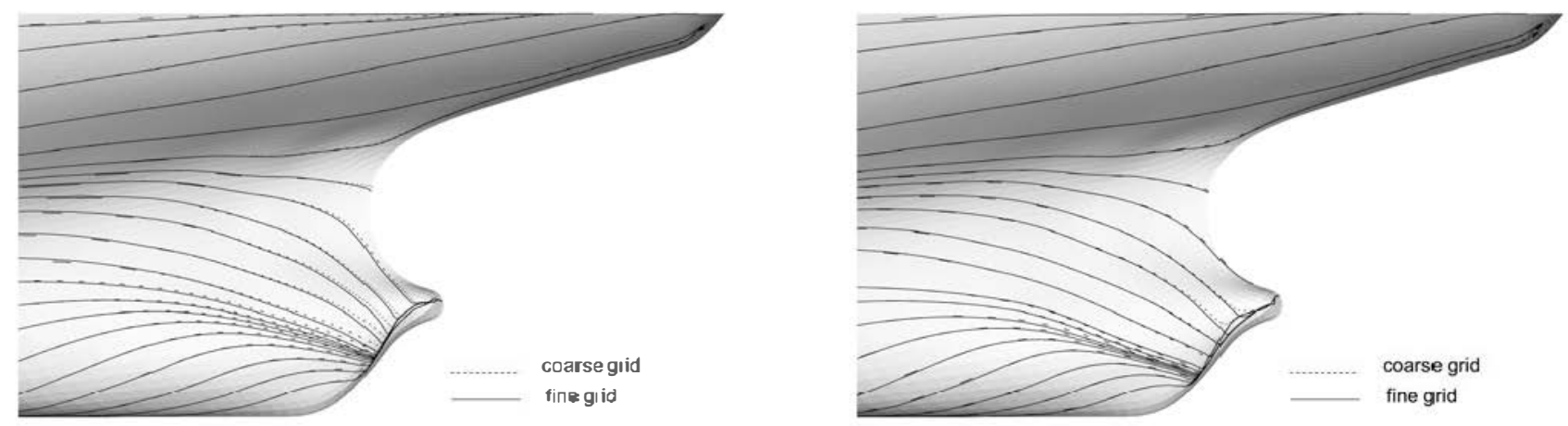

Fig.6: Streamlines for the SST $k-\omega$ (left) and $R_{i j}-\omega$ (right) models
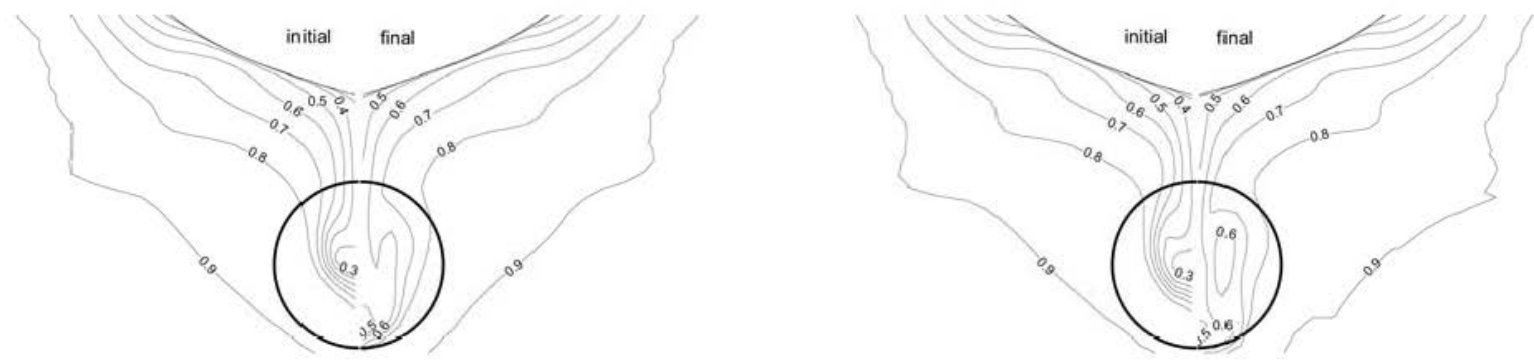

Fig.7: Isowakcs for the SS'I $k-\omega$ (lcft) and $R_{i j}-\omega$ (right) models
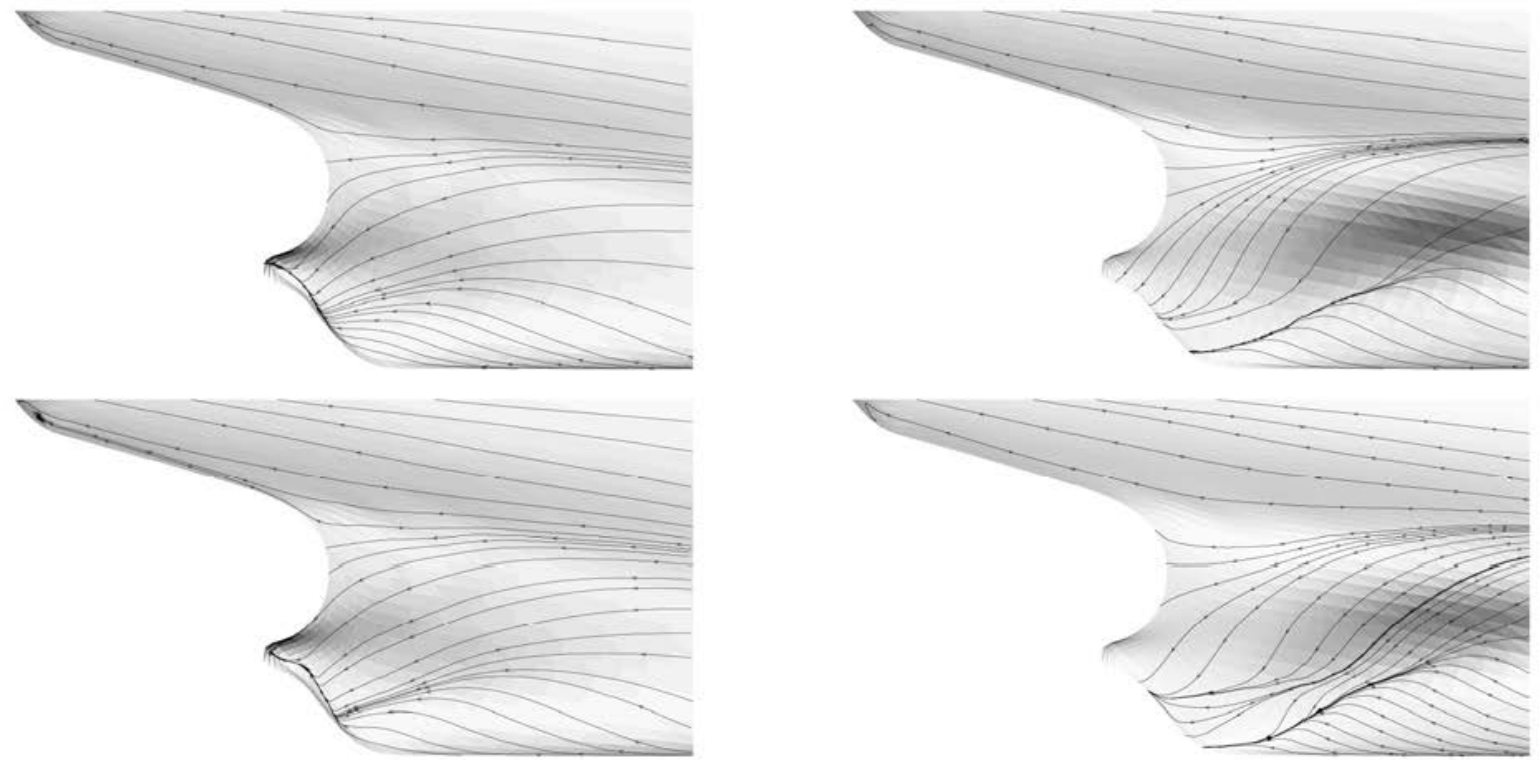

Fig.8: Streamlines for the SST $k-\omega$ (top) and $R_{i} j^{-\omega}$ (bottom) models 
To illustrate the influence of turbulence modeling during the design process, a realistic hull shape optimization problem is considered. The flow around the KVLCC2 tanker of length $l$ is computcd at full scale $\left(R_{\pi}=10^{9}\right)$, using a structured mesh of about 400,000 control volumes. Twe turbulence models arc tested: the cddy-viscosity SST $k-\omega$ model of Menter and a sccond-order closurc $R_{i j}-\omega$ model. The twe models give different predictions of the wake, Deng and Visonneau (2000), the longitudinal vortex gencratcd being intensificd by the sccond-order closurc. However, thesc differences are less important at full scale than at medel scale. To validate the full-scale results, computations are performed with a fincr grid of about onc million nodes, Figs.5 and 6. Grid convergence is almost reached for both turbulence models and differences between considered turbulence models are far more important than numerical errors. For the sake of pragmatism, shape optimization computations are performed with the coarser grid.

The goal of the optimization is to homogenize the longitudinal velocity field at the location of the propeller, modifying the stern of the ship described by 6 design variables. This exercise consists in reducing the mean deviation of the longitudinal component of the velocity, computed in the prepeller disk. One intends to quantify the influence of the turbulence modeling during the optimization process. Since preliminary tests show that the topoløgy of the objective function is quite simple, a deterministic optimization algorithm based on linear or quadratic interpolations is used, Marazzi and Nocedal (2002).

Fig.7 shows the isowakes for the initial and final shapes. The optimal shapes are characterized by a far mere intense longitudinal vertex homogenizing the flow. This evelution during the design process enforces the influence of the turbulence modeling. Fig. 8 represents the streamlines close to the wall. The topology of the flow has changed and is finally similar to model scalc flows. Thus, somc differences between the models appear even at full scale. Looking at the optimized shapes, Fig.9, at $x=0.94 l$, similar trends arc obtaincd. Differences arc duc to the fact that the usc of sccond-order closure leads to a flow characterized by a stronger longitudinal vorticity in the near wake. Therefore, lower medifications of the shape may gencratc a more intense vortcx. The final shapes give U-shaped sections. The evolution of the objective function, Fig.10, shows a reduction of about $70 \%$ of the velocity mean deviation at the propeller location. The reduction is smaller for the second-order closure. This phenomenon is maybe due to the presence of more complex turbulence structures in the wake, not described by the linear eddy-viscosity model.

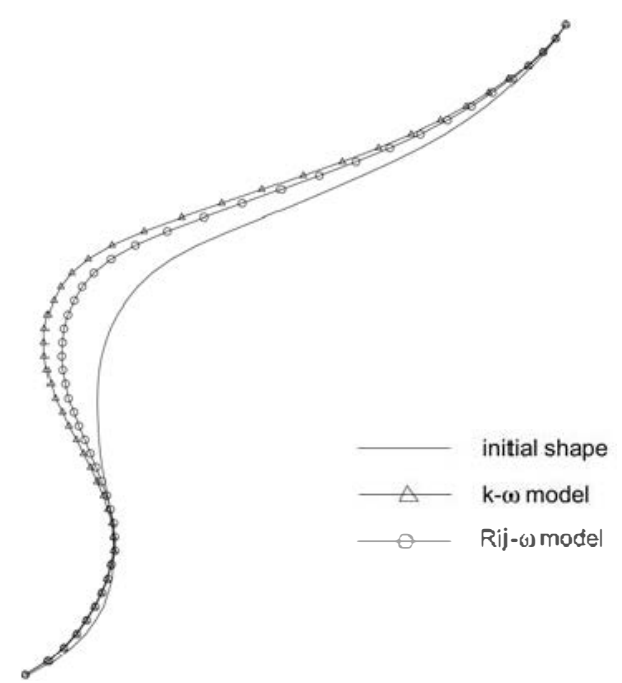

Fig.9: Initial and final shapes at $x=0.94 l$

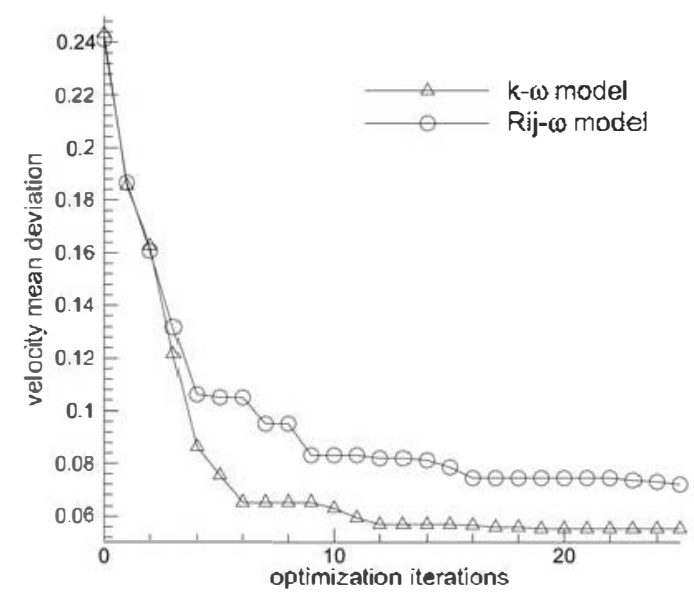

Fig.10: Evolution of the objectivc function

This example underlines the influence of turbulence modeling in the framework of hull shape optimization. Although less important at full scale, the turbulence model still has a crucial influence, when local characteristics of the flow in critical regions are considered during the optimization. 


\section{Conclusion}

This study explored different strategies to solve shape optimization problems involving complex flow solvers. The choice of the optimizer has crucial consequences. Genetic algorithms have several advantages over deterministic approaches. Their use is now realistic, providing that acceleration techniques are employed, such as hybridization and inexact pre-evaluations through artificial neural networks. Some practical difficulties still exist, e.g. the mesh update for 3-d problems. However, the main limitation may be the influcnec of turbulcnce modeling on the design process for some problcms, since this modeling error cannot be reduced, centrary to other numerical parameters, such as grid size or partial convergence.

\section{References}

A.NDERSON, W.K.; VENKATAKRISH.NA.v, V. (1999), Aerodynamic design optimization on unstructured grids with a continuous adjoint formulation, Computers and Fluids 28/4, pp.443-480

CHEN, P.F.; HUANG, C.H. (2002), An inverse hull design problem in optimizing the desired wake of a ship, J. Ship Research 46/2,pp. 138-147

DENG, G.; VISONNEAU, .M. (2000), Comparison of explicit algebraic stress models and second-order turbulence closures for steady flows around the KVLCC2 ship at model and full scales, Gothenborg 2000 Workshop (Eds. Larsson, Stern, Bertram), Chalmers Univ. Technology, Göteborg

DUVIGNEAC, R.; VISONNEAU, M. (2001a), Shape optimization for incompressible and turbulent flows using the Simplex method, AIA A Papcr 2001-2533

DUVIGNEAC, R.; VISONNEAU, M. (2001b), Single- and multi-objective optimization for high-fidelity CFD using genetic algorithms, ECROGEN 2001: Evolutionary Methods for Design, Optimisation and Control with Applications to Industrial Problems

DUVIG.VEAC, R.; VISONNEAU, M. (202), Hybrid genetic algorithms and neural networks for fast CFD-based design, AIAA Paper 2002-5465

DUVIG.NEAC, R.; VISON.NEAC, M. (2003), Shape optimization strategies for complex applications in computational fluid dynamics, $2^{\text {nd }}$ Conf. Computer and IT Appl. Mar. Ind. (COMPIT), Hamburg, pp.154-161

DUVIG.NEAC, R.; VISONNEAU, M.; DENG, G.B. (2002), On the role played by turbulence closures in hull shape optimization at model and full scale, $24^{\text {th }}$ Symp. Naval Hydrodynamics, Fukuokat

FARHAT, C.; DEGAND, C.; KOOBLS, B.; LESOINNE, M. (1998), Torsional springs for two dimensional dynamic unstructured fluid meshes, Computational Methods in Applied Mech. and Eng., pp.231-245

GIOTIS, A.P.; GIA.NNAKOGLOU, K.C. (1999), Single- and multi-objective airfoil design using genetic algorithms and artificial intelligence, ELROGEN 99: Evolutionary Algorithms in Engineering and Computer Science, John Wilcy \& Sons

GIOTIS, A.P.; GIANNAKOGLOU, K.C. (2000), Acceleration of genetic algorithms using artificial neural networks, VKI Lecture Series: Genetic Algorithms for Optimization in Aeronautics and Turbomachinery

GOLDERG, D.E. (1989), Genetic algørithms in search, optimization and machine learning, Addison Wesley

HENDRIX, D.; PERCIVAL, S.; NOELESSE, F. (2001), Practical hydrodynamic optimization of a monohull, S.NAME Annual Meeting, Orlando, Florida

HINO, T. (1999), Shape optimization of practical ship hull forms using Navier-Stokes analysis, 7. Int. Conf. Num. Ship Hydrodyn., Nantes

HOSDER, S.; GROSSMAN, B.; HAFTKA, R.; MASON, W.; WATSON, L. (2002), Observations on CFD simulation uncertainties, AIAA paper 2002-5531

HOVLAND, P.; MOHAMMADI, B.; BISCHOF, C. (1997), Automatic differentiation and Navier-Stokes computation, ANL/MCS P687-0997, Mathematics and Computer Scicnce Division, Argonc Nat. Lab.

JANSON, C.E.; LARSSON, L. (1996), A method for the optimization of ship hulls from a resistance point of view, 21. Symp. Naval Hydrodyn., Trondheim

JAMESON, A.; MARTINELLI, L.; PIERCE, N.A. (1998), Optimum aerdynamic design using the Navier- 
Stokes equation, Theor. and Comp. Fluid Dyn. 10, pp.213-237

KITA.MURA, M.; NOBUKAWA, H.; YANG, F. (2000), Application of genetic algorithms to the optimal structural design of a ship's engine room takin dynamic constraints int consideration, J. Marine Science and tcchnology 5/3, pp.131-146

MADSEN, J.I. (2000), Response surface techniques for diffuser shape optimization, AIAA .J. 38/9, pp.1512-1518

MAISONNEUVE, J.J.; HILLS, D.P.; .MORELLE, P.; FLLRY, C.; SCHOOFS, A.J.G. (1996), A shape optimisation toal for multi-disciplinary industrial design, ECC()MAS'96, John Wiley\&.Sons

MAISONNEUVE, J.J. (2002), Towards ship performance improvement using modeFRONTIER, 5. Num. Towing Tank Symp. (NuTTS’02), Pornichet,

MARAZZI, M.; NOCEDAL, J. (2002), Wedge trust region methods for derivative-free optimization, Mathematical Programming 91/2, pp.289-305

MOHAMMADI, B. (1999), Dynamical appreaches and incomplete gradients for shape optimization and flow control, AIAA paper 99-3374

MOHAMMADI, B.; KOBLS, B.; PUIGT, G. (2000), Distributed 3D shape optimization with incomplete sensitivities and CAD-free framework for high-speed inviscid and viscous turbulent regimes, AIAA paper 20004526

MENTER, F.R. (1993), Zonal two-equations $k$ - $\omega$ turbulence models for aeredynamic flows, AIAA paper 93-2906

NELDER, J.A.; MEAD, R. (1965), A Simplex method for function minimization, Computer Journal 7, pp.308313

PERI, D.; R.OSETTI, M.; CAMPANA, E. (2000): An example of ship hull optimization via numerical techniques, COMPIT'2000, Potsdam, pp.364-379

PERI, D.; ROSETTI, M.; CAMPANA, E. (2001), Design optimization of ship hulls vi CFD techniques, J. Ship Rescarch 45, pp.140-149

ROSETTI. M.; PERI, D.; CAMPANA, E. (1999), Numerical ship hull optimization, NiuTTS`99, R॰me

SEDERBERG, T.W.; PARRY, S.R. (1986), Free-form deformation of solid geometric models, Computer Graphics $20 / 4$, pp.151-160

SPALART, P.R.; ALLMARAS, S.R. (1991), A one-equation turbulence model for aerodynamic flows, AIAA Paper 92-0439

YASUKAWA, H. (2000), Ship form improvement using genetic algorithm, Ship Technology Research 47, pp.3544 